\title{
Terapia fotodinâmica no tratamento endodôntico: Uma revisão integrativa
}

\author{
Photodynamic therapy in endodontic treatment: An integrative review \\ Terapia fotodinámica en tratamiento endodôntico: Una revisión integrativa
}

Recebido: 12/07/2021 | Revisado: 19/07/2021 | Aceito: 23/07/2021 | Publicado: 31/07/2021

Renally Bezerra Wanderley e Lima
ORCID: https://orcid.org/0000-0003-4477-7850
Faculdades Nova Esperança, Brasil
E-mail: renallywanderley @ gmail.com
Marcelo dos Santos Silva
ORCID: https://orcid.org/0000-0002-7631-7691
Faculdades Nova Esperança, Brasil
E-mail: marcellosaude@ @otmail.com
João Gabriel Regis da Silva
Faculdades Nova Esperança, Brasil
E-mail: regis0934@ gmail.com
Juan Vitor Costa Leite
ORCID: https://orcid.org/0000-0002-1361-4904
FRCID: https://orcid.org/0000-0002-6069-6703
Faculdades Nova Esperança, Brasil
E-mail: juan.leit@ @otmail.com
Fernanda Clotilde Mariz Suassuna
ORCID: https://orcid.org/0000-0001-5846-288X
Faculdades Nova Esperança, Brasil
E-mail: fernandaCosta3@ @ hotmail.com
Jussara da Silva Barbosa
ORCID: https://orcid.org/0000-0001-6123-5266
Faculdades Nova Esperança, Brasil
E-mail: barbosajsara@ gmail.com

\section{Resumo}

A terapia fotodinâmica (TFP) é uma terapêutica coadjuvante, na qual existe a interação entre uma fonte de luz específica, um agente fotossensibilizante e o oxigênio molecular para desencadear a morte celular. O objetivo desta revisão integrativa foi realizar um levantamento de evidências científicas sobre a eficácia da TFP como complementar na limpeza dos canais radiculares. Foram realizadas buscas sistemáticas nas bases de dados LILACS e BBO, utilizando as seguintes palavras-chaves: ("terapia fotodinâmica") OR ("fotoquimioterapia") AND (endodontia) OR ("terapia endodôntica"). Os critérios de inclusão foram: estudos que utilizaram a TFD como coadjuvante ao tratamento endodôntico e estudos que avaliaram seus efeitos. Como critérios de exclusão: aqueles que não utilizaram nenhum instrumento ligado aos objetivos proposto deste estudo; capítulos de livros; resumos de conferências (anais); revisões nacionais ou internacionais e textos completos, mas não publicados em revistas credenciadas. De acordo com os resultados, os lasers mais utilizados foram os de Diodo de baixa potência de $40 \mathrm{~mW}$ a $100 \mathrm{~mW}$, com frequências entre 500 a $810 \mathrm{~nm}$. O intervalo de tempo utilizado nos estudos foi de 40 a 240s. A frequência mais aplicada foi de $660 \mathrm{~nm}$. O protocolo de aplicação mais utilizado foi com o fotossensibilizador azul de metileno. A TFP mostra-se promissora como coadjuvante ao tratamento endodôntico convencional. Embora, os estudos na literatura demonstrem resultados promissores do uso da TFD na desinfecção endodôntica ainda é necessário a realização de mais pesquisas, principalmente clínicas, para definir com clareza e segurança um protocolo terapêutico na prática clínica diária.

Palavras-chave: Terapia fotodinâmica; Fotoquimioterapia; Endodontia.

\begin{abstract}
Photodynamic therapy (PDT) is an adjunctive therapy which exist an interaction between a specific light source, a photossensitizing agent and the molecular oxygenation to trigger cell death. This integrative review aimed to evaluate scientific evidence regarding the effectiveness of PDT as a complement for cleaning root canals. Systematic surveys were carried out at LILACS and BBO databases, using the following words: ("photodynamic therapy") OR ("photochemotherapy") AND (endodontics) OR ("endodontic therapy"). The criteria of inclusion were studies using PDT as a coadjuvant for endodontic treatment and studies evaluating PDT effects. Studies did not use any instrument linked to this study purpose, book chapters, conference summaries, national or international reviews and full texts not published in accredited journals were excluded. According to the results, the most used lasers was Diode of low power from $40 \mathrm{~mW}$ to $100 \mathrm{~mW}$, with frequencies between 500 to $810 \mathrm{~nm}$. The range time used in the include studies was 40 to 240s. The most applied frequency was $660 \mathrm{~nm}$. The most used application protocol used methylene blue as
\end{abstract}


photossensitizer. PDT shows promise as an adjunct for conventional endodontic treatment. However, promising results were observed from PDT in endodontic disinfection, future investigations should be carry out, mainly clinical, to define a clear and safe therapeutic protocol for daily clinical practice.

Keywords: Photodynamic therapy; Photochemotherapy; Endodontics.

\section{Resumen}

La terapia fotodinámica (PFT) es una terapia adyuvante, la interacción entre una fuente de luz específica, un agente fotosensibilizante y el oxígeno molecular para desencadenar la muerte celular. El objetivo de esta revisión integradora fue realizar una encuesta de evidencia científica sobre la efectividad de la PTF como complemento en la limpieza de conductos radiculares. Se realizaron búsquedas sistemáticas en las bases de datos LILACS y BBO, utilizando las siguientes palabras clave :( "terapia fotodinámica") OR ("fotoquimioterapia") Y (endodoncia) OR ("terapia endodóntica"). Los criterios de inclusión fueron: estudios que utilizaron la TFD como complemento del tratamiento endodóntico y estudios que evaluaron sus efectos. Como criterios de exclusión: los que no utilizaron ningún instrumento vinculado a los objetivos propuestos de este estudio; capítulos de libros; resúmenes de conferencias (anales); revisiones y textos completos nacionales o internacionales, pero no publicados en revistas acreditadas. Según los resultados, los láseres más utilizados fueron los láseres de diodo de baja potencia de $40 \mathrm{~mW}$ a $100 \mathrm{~mW}$, con frecuencias entre 500 y $810 \mathrm{~nm}$. El intervalo de tiempo utilizado en los estudios fue de 40 a 240 segundos. La frecuencia más aplicada fue de $660 \mathrm{~nm}$. El protocolo de aplicación más utilizado fue con el fotosensibilizador de azul de metileno. La TFP se muestra prometedora como complemento del tratamiento de endodoncia convencional. Aunque los estudios en la literatura demuestran resultados prometedores del uso de la TFD en la desinfección endodóntica, aún se necesitan más investigaciones, especialmente clínicas, para definir de manera clara y segura un protocolo terapéutico en la práctica clínica diaria.

Palabras clave: Terapia fotodinámica; Fotoquimioterapia; Endodoncia.

\section{Introdução}

A saúde bucal passou por diversas modificações nas técnicas e procedimentos nas diferentes áreas da Odontologia, dentre elas a endodontia. Alguns procedimentos endodônticos, como o tratamento de dentes com rizogênese incompleta e necrose pulpar, representam um grande desafio para a terapia endodôntica (Albuquerque, 2012). Vários protocolos estão sendo abordados com o intuito de promover a regeneração do tecido pulpar e a sua desinfecção, para isso, uma ação mínima de um instrumento no canal radicular com abundante irrigação do mesmo são necessárias para proporcionar o controle da infecção e a eliminação de sintomas (Torabinejad \& Turman, 2011).

A tecnologia e seus benefícios proporcionam uma linha de mudanças nas técnicas odontológicas, trazendo inovações que favorecem significativamente os tratamentos propostos na Odontologia (Viana, 2011). Na área da Endodontia esses avanços tecnológicos possibilitaram que o tratamento endodôntico fosse realizado em uma única sessão, independente do estado da polpa, pois a aplicação de um protocolo preciso e criterioso permite obter o total controle da infecção e da sintomatologia dolorosa (Mortoza, 2015). O tratamento endodôntico convencional, realizado com o desbridamento mecânico combinado com a irrigação química, não remove completamente os microrganismos do interior do canal. Assim, para complementar a limpeza dos canais, outras terapias, como a terapia fotodinâmica, estão sendo aplicadas (Soukos et al., 2006).

A terapia fotodinâmica (TFD) surgiu como um novo modelo de terapia, a qual interage em uma harmonia de tríade entre uma fonte de luz específica, um agente fotossensibilizante e o oxigênio molecular para desencadear a morte celular (Garcez et al., 2008). A TFD pode apresentar uma ação de estímulo a regeneração tecidual e desinfecção dos canais radiculares. Esta modalidade terapêutica é considerada uma inovação na área da Odontologia, onde o corante é transferido à molécula de oxigênio, originando assim uma reação oxidativa, o qual posteriormente ocorre dois mecanismos principais de reação a partir do seu estado excitado (Amaral et al., 2019).

A grande finalidade do tratamento endodôntico na atualidade é eliminar o máximo de bactérias previamente à obturação. Pesquisas atuais demonstram que o sucesso do tratamento endodôntico está relacionado diretamente à proporção de eliminação de bactérias durante o tratamento (Melo, 2016). Canais radiculares infectados apresentam uma complexa flora 
microbiana distribuída na extensão dos canais radiculares principais e secundários. Essas coleções ou agregados densos microbianos (biofilme) se aderem às paredes dos canais e são capazes de penetrar a dentina através dos túbulos dentinários.

$\mathrm{O}$ insucesso do tratamento endodôntico ocorre, na maioria das vezes, por falhas causadas devido à anatomia de difícil acesso ou presença de canais secundários, onde a descontaminação torna-se mais restrita (Eduardo et al., 2015). Dentro desse contexto pode-se pensar que a TFD poderia apresentar eficácia como terapia complementar para limpeza dos canais radiculares no tratamento endodôntico.

Um levantamento da evidência científica de literatura sobre a importância e benefícios da TFD na endodontia é necessário para potencializar os resultados dos procedimentos convencionais como limpeza de canais radiculares secundários infectados. Portanto, este estudo tem a finalidade de nortear os cirurgiões dentistas sobre a possibilidade de utilizar a TFD como coadjuvante do tratamento endodôntico, bem como: descrever e analisar os tipos de lasers mais utilizados na TFD; especificar e analisar as potências e comprimentos de onda nas ações do TFD e detalhar os tipos de fotossensibilizantes mais utilizados na TFD.

\section{Metodologia}

Esta revisão integrativa possui caráter qualitativo e inclui a análise de pesquisas sistematizadas relevantes que dão suporte para a tomada de decisão e a melhoria da prática clínica, possibilitando a síntese do estado do conhecimento de um determinado assunto, além de apontar lacunas do conhecimento que precisam ser preenchidas com a realização de novos estudos (Mendes et al., 2008) Além disso, sintetiza resultados de pesquisas anteriores sobre um fenômeno específico, consentindo que se obtenham conclusões gerais sobre a temática proposta (Crossetti, 2012).

\subsection{Estratégia de busca}

A pergunta de pesquisa desta revisão integrativa foi: $\mathrm{O}$ uso da TFD como coadjuvante para limpeza dos canais radiculares é eficaz? Para realização da mesma, buscas sistemáticas em base de dados nacionais, como LILACS e BBO, utilizando as seguintes palavras-chaves e estratégia de busca: ("terapia fotodinâmica") OR ("fotoquimioterapia") AND (endodontia) OR ("terapia endodôntica") foram realizadas.

\subsection{Critérios de elegibilidade}

Como critérios de inclusão da presente revisão integrativa foram utilizados: estudos que utilizaram a TFD como terapia coadjuvante ao tratamento endodôntico e estudos que avaliaram o efeito da TFD na limpeza dos canais radiculares. Foram considerados critérios de exclusão: aqueles que não utilizaram nenhum instrumento ligado aos objetivos propostos de forma geral e específica deste estudo, capítulos de livros, resumos de conferências (anais), revisões nacionais ou internacionais e textos completos, mas não publicados em revistas credenciadas ou reconhecidas.

\subsection{Seleções dos estudos e extração dos dados}

Para a elaboração dos resultados foi realizada a identificação das duplicatas $(n=0)$ pelos títulos dos artigos, sem critérios de filtros de linguagem e de ano de publicação. Em seguida, a leitura dos artigos e resumos foi realizada e categorizadas de acordo com os critérios de elegibilidade. Os trabalhos incluídos foram selecionados para leitura completa e detalhada dos textos completos.

Uma planilha padronizada do Microsoft word, foi utilizada para descrever os dados metodológicos mais importantes dos estudos incluídos. Os seguintes dados coletados nos estudos selecionados: autor, ano de publicação, nome do país, tipo de laser, comprimento de onda, potência do laser, tempo de aplicação do laser, tipo de fotossensibilizante, espécie bacteriana, tipo 
de estudo, tratamento principal e os principais resultados dos estudos incluídos. Este tipo análise dos objetivos e resultados dos estudos permitem obter informações sobre o tema central e ainda sintetizar de forma clara e concisa os próprios resultados.

\subsection{Análise dos dados}

Os dados obtidos dos estudos que preencheram os critérios de inclusão foram avaliados por meio de uma síntese qualitativa e detalhada das evidências incluídas.

\section{Resultados}

\subsection{Pesquisa e seleção dos estudos}

O fluxograma PRISMA que resume a estratégia de busca dos estudos está reprersentado na Figura 1. No total, 28 artigos foram selecionados em todas as bases de dados acima citadas. Após a leitura de titulos e resumo, dos artigos selecionados, 8 estudos foram excluidos, pois não estavam ligados aos objetivos proposto de forma geral e específica. A próxima etapa foi a leitura e avaliação completa dos artigos potencialmente elegíveis. De acordo com os critérios de inclusão, 14 estudos foram incluídos na análise qualitativa do presente trabalho, pois para dois estudos os textos completos dos artigos estavam indisponíveis para a leitura e extração dos dados. Solicitações via e-mail foram realizadas aos autores para a obtenção dos textos, mas nenhuma resposta foi obtida.

Figura 1. Fluxograma sumarizando o processo de seleção e identificação dos estudos (PRISMA).

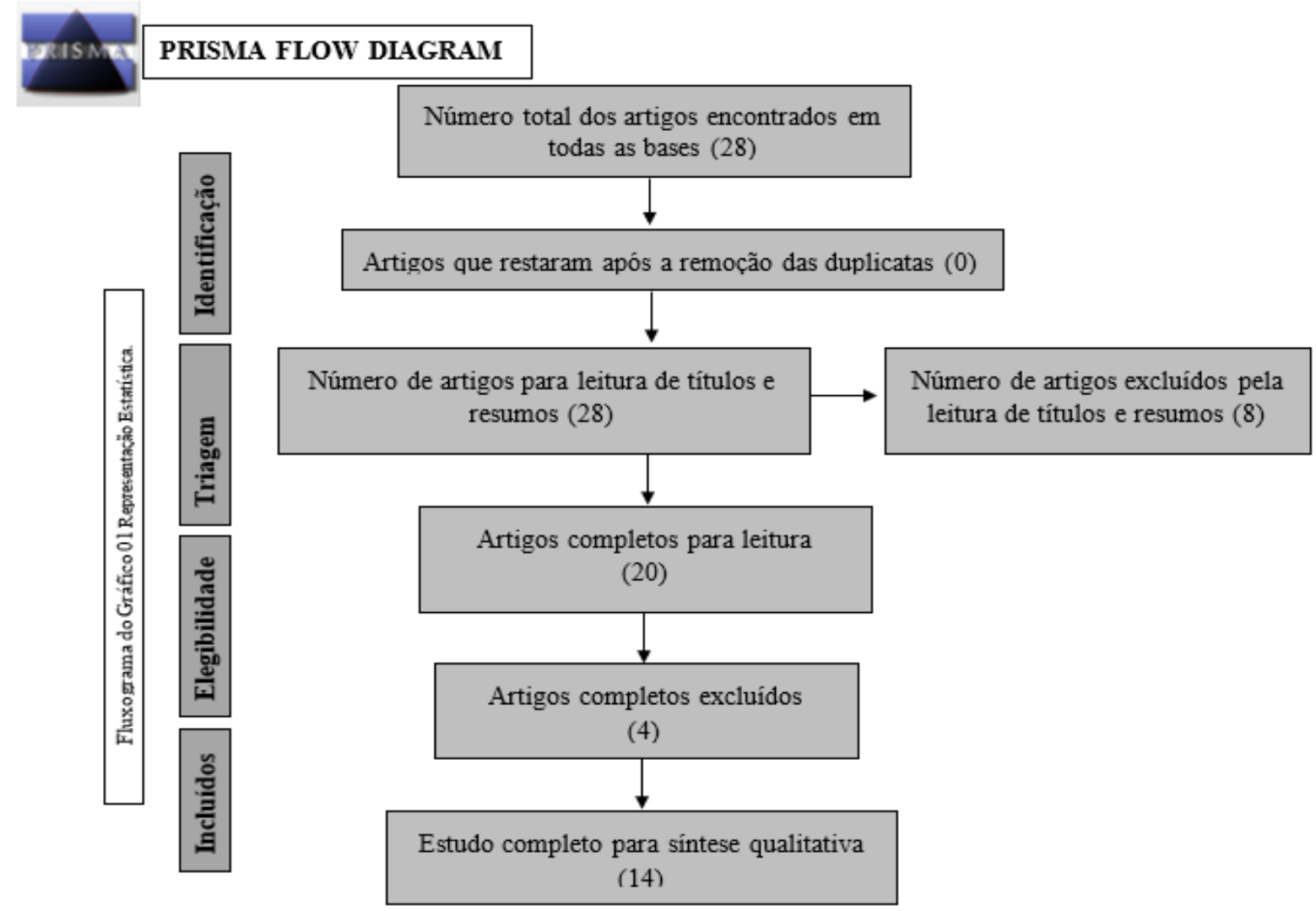

Fonte: Adaptado de Moher et al. (2009).

\subsection{Análise qualitativa}

De acordo com a análise qualitativa feita com o levantamento dos dados metodológicos dos estudos incluídos, os estudos foram publicados entres os anos de 2008 a 2019. Os lasers mais utilizado nos estudos foram os lasers de Diodo de 


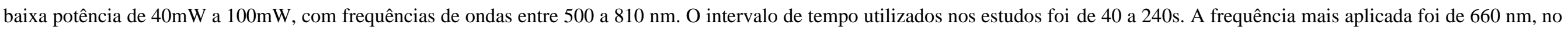

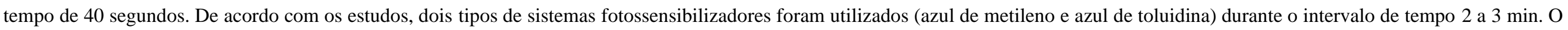
protocolo de aplicação mais utilizado foi com o fotossensibilizador azul de metileno no tempo de 3 min (Tabela 1).

Tabela 1. Principais dados metodológicos e resultados extraídos dos estudos incluídos.

\begin{tabular}{|c|c|c|c|c|c|c|c|c|c|c|c|}
\hline Autor & Ano & País & Tipo de laser utilizado & $\begin{array}{l}\text { Comprimento } \\
\text { de onda }\end{array}$ & $\begin{array}{c}\text { Potência } \\
(\mathrm{mw})\end{array}$ & $\begin{array}{c}\text { Temp } \\
\text { o } \\
\text { de } \\
\text { aplicaçã } \\
\text { o }\end{array}$ & Fotossensibilizador & $\begin{array}{c}\text { Espécie } \\
\text { bacteriana }\end{array}$ & $\begin{array}{l}\text { Tipo de } \\
\text { estudo }\end{array}$ & $\begin{array}{c}\text { Tratamento } \\
\text { principal }\end{array}$ & $\begin{array}{l}\text { Conclusões ou } \\
\text { resultados }\end{array}$ \\
\hline $\begin{array}{l}\text { Santa-rosa } \\
\text { et al. }\end{array}$ & 2019 & Brasil & $\begin{array}{l}\text { Laser vermelho Duo } \\
\text { MM Optics de baixa } \\
\text { potência }\end{array}$ & $660 \mathrm{~nm}$ & $40 \mathrm{mw}$ & $60 \mathrm{~s}$ & $\begin{array}{l}\text { Azul de metileno } \\
(50 \mathrm{mg} / \mathrm{l}) \text { por } 3 \mathrm{~min}\end{array}$ & E. Faecalis & In vitro & $\begin{array}{l}\text { Tratamento } \\
\text { endodôntico } \\
\text { convencional }\end{array}$ & $\begin{array}{c}\mathrm{NaOCl} \text { na TFD } \\
\text { apresentaram melhor } \\
\text { desempenho em relação } \\
\text { aos demais. }\end{array}$ \\
\hline $\begin{array}{l}\text { Eduardo et } \\
\text { al. }\end{array}$ & 2015 & Brasil & $\begin{array}{l}\text { Laser vermelhos laser } \\
\text { duo } \\
\text { MM Optics de baixa } \\
\text { potência e Led vermelho }\end{array}$ & $664 \mathrm{~nm}$ & $100 \mathrm{mw}$ & $90 \mathrm{~s}$ & Azul de metileno por $3 \mathrm{~min}$ & E. Faecalis & In vivo & $\begin{array}{l}\text { Tratamento } \\
\text { endodôntico } \\
\text { convencional }\end{array}$ & $\begin{array}{l}\text { Através dos estudos } \\
\text { descritos na revisão de } \\
\text { literatura, pode-se } \\
\text { considerar a terapia } \\
\text { fotodinâmica como uma } \\
\text { terapia coadjuvante } \\
\text { promissora para ser } \\
\text { aplicada à odontologia. }\end{array}$ \\
\hline Rosa & 2008 & Brasil & Lasers de diodo & $660 \mathrm{~nm}$ & $40 \mathrm{mw}$ & $60 \mathrm{~s}$ & $\begin{array}{l}\text { Azul de metileno, } \\
\text { azul de toluidina } \\
\text { e azuleno } \\
\text { por } 3 \mathrm{~min}\end{array}$ & Candida albicans & In vivo & $\begin{array}{l}\text { Tratamento } \\
\text { endodôntico } \\
\text { convencional }\end{array}$ & $\begin{array}{c}\text { A instrumentação } \\
\text { associada a TFD } \\
\text { antimicrobiana frente a } e . \\
\text { Faecalis e Escherichia } \\
\text { coli foi efetiva, } \\
\text { Mas não apresentou } \\
\text { efetividade frente a } \\
\text { Candida } \\
\text { albicans }\end{array}$ \\
\hline Garcez & 2016 & Brasil & Lasers de diodo & $666 \mathrm{~nm}$ & $40 \mathrm{mw}$ & $\begin{array}{c}30 \mathrm{a} \\
240 \mathrm{~s}\end{array}$ & $\begin{array}{l}\text { Azul de metileno por } 1 \mathrm{~min} \\
\text { até } 2,40 \mathrm{~min}\end{array}$ & $\begin{array}{c}\text { E. Faecalis } \mathrm{e} \\
\text { Candida albicans }\end{array}$ & In vitro & $\begin{array}{l}\text { Tratamento } \\
\text { endodôntico } \\
\text { convencional }\end{array}$ & $\begin{array}{l}\text { A indicação e uso da a } \\
\text { TFD na redução } \\
\text { bacteriana intracanal tem } \\
\text { sido comprovado por } \\
\text { diversos estudos na } \\
\text { literatura, entretanto, não } \\
\text { há consenso sobre os } \\
\text { parâmetros ideais. }\end{array}$ \\
\hline Alfenas et al. & 2011 & Brasil & Lasers de diodo & $660 \mathrm{~nm}$ & $40 \mathrm{mw}$ & $240 \mathrm{~s}$ & $\begin{array}{l}\text { Azul de metileno por } 5 \mathrm{~min} \\
5\end{array}$ & $\begin{array}{c}\text { E. Faecalis } \mathrm{e} \\
\text { Candida albicans }\end{array}$ & In vitro & $\begin{array}{l}\text { Tratamento } \\
\text { endodôntico } \\
\text { convencional }\end{array}$ & $\begin{array}{l}\text { A TFD não deve substituir } \\
\text { os procedimentos dos } \\
\text { tratamentos } \\
\text { convencionais, mas deve }\end{array}$ \\
\hline
\end{tabular}




\begin{tabular}{|c|c|c|c|c|c|c|c|c|c|c|c|}
\hline & & & & & & & & & & & é seguro. \\
\hline Santos & 2017 & Brasil & Lasers de diodo & 500 a $600 \mathrm{~nm}$ & $40 \mathrm{mw}$ & $\begin{array}{l}30 \mathrm{a} \\
240 \mathrm{~s}\end{array}$ & Azul de metileno por $2 \mathrm{~min}$ & $\begin{array}{c}\text { E. Faecalis } \mathrm{e} \\
\text { Candida albicans }\end{array}$ & $\begin{array}{c}\text { In vitro e in } \\
\text { vivo }\end{array}$ & $\begin{array}{l}\text { Tratamento } \\
\text { endodôntico } \\
\text { convencional }\end{array}$ & $\begin{array}{c}\text { A TFD mostra-se } \\
\text { promissora como } \\
\text { coadjuvante ao tratamento } \\
\text { endodôntico } \\
\text { convencional. Fazem-se } \\
\text { necessárias mais } \\
\text { pesquisas. }\end{array}$ \\
\hline $\begin{array}{l}\text { Ane Poly et } \\
\text { al. }\end{array}$ & 2010 & Brasil & Lasers de diodo & $660 \mathrm{~nm}$ & $40 \mathrm{mw}$ & - & Azul de metileno & E. Faecalis & In vitro & $\begin{array}{l}\text { Tratamento } \\
\text { endodôntico } \\
\text { convencional }\end{array}$ & $\begin{array}{c}\text { TFD se mostrou } \\
\text { aparentemente mais eficaz } \\
\text { que o laser no controle da } \\
\text { infecção. As terapias } \\
\text { demonstraram ser aliadas } \\
\text { promissoras ao tratamento } \\
\text { convencional no controle } \\
\text { da infecção endodôntica } \\
\text { com e. Faecalis }\end{array}$ \\
\hline $\begin{array}{l}\text { Almeida et } \\
\text { al. }\end{array}$ & 2019 & Brasil & - & - & - & $40 \mathrm{~s}$ & - & E. Faecalis & In vivo & $\begin{array}{l}\text { Irrigação passiva } \\
\text { ultrassônica, } \\
\text { Endovac } \\
\text { Sistema self- } \\
\text { adjusting file } \\
\text { XP Endo Finisher }\end{array}$ & $\begin{array}{l}\text { Além disso, todos, com } \\
\text { exceção da TDF e da } \\
\text { irrigação final com } \\
\text { clorexidina, são altamente } \\
\text { efetivos na remoção de } \\
\text { detritos dentinários ou } \\
\text { medicação intracanal em } \\
\text { comparação com a } \\
\text { irrigação convencional }\end{array}$ \\
\hline Simões et al. & 2018 & Brasil & Lasers de diodo & $810 \mathrm{~nm}$ & $40 \mathrm{mw}$ & $40 \mathrm{~s}$ & Azul de metileno & E. Faecalis & In vitro & $\begin{array}{l}\text { Tratamento } \\
\text { endodôntico } \\
\text { convencional }\end{array}$ & $\begin{array}{l}\text { Embora a TFD não possa } \\
\text { ser usada de forma isolada } \\
\text { nas infecções pulpares, } \\
\text { diversos estudos a } \\
\text { evidenciaram como } \\
\text { coadjuvante eficaz no } \\
\text { tratamento endodôntico, }\end{array}$ \\
\hline Solano et al. & 2017 & & - & - & - & $\begin{array}{l}30 \mathrm{a} \\
240 \mathrm{~s}\end{array}$ & $\begin{array}{l}\text { Azul de metileno e azul de } \\
\text { toluidina por } \\
5 \mathrm{~min}\end{array}$ & - & In vitro & $\begin{array}{l}\text { Convencional } \\
\text { Uso de azul de } \\
\text { metileno a } 2 \% \\
\text { sozinho ou associado } \\
\text { a lauril sulfato de } \\
\text { sódio a } 0,125 \% .\end{array}$ & $\begin{array}{c}\text { Não há diferença } \\
\text { significativa na } \\
\text { penetraçãa do } \\
\text { fotossensibilizador entre a } \\
\text { aplicação convencional e } \\
\text { a aplicação aprimorada } \\
\text { por sonicação. }\end{array}$ \\
\hline Araújo et al. & 2013 & Brasil & - & $660 \mathrm{~nm}$ a $685 \mathrm{~nm}$ & - & - & $\begin{array}{c}\text { Azul de metileno e azul de } \\
\text { toluidina } \\
\text { Por } 3 \text { a } 4 \text { min }\end{array}$ & E. Faecalis & In vitro & $\begin{array}{l}\text { Tratamento } \\
\text { endodôntico } \\
\text { convencional }\end{array}$ & $\begin{array}{l}\text { Aplicação de laser ou led } \\
\text { são eficazes, mais } \\
\text { necessita de mais estudos. }\end{array}$ \\
\hline Santos et al. & 2017 & Usa & $\begin{array}{l}\text { Whithening laser II de } \\
\text { baixa intensidade }\end{array}$ & $660 \mathrm{~nm}$ & $100 \mathrm{mw}$ & $40 \mathrm{~s}$ & $\begin{array}{l}\text { Corante azul de lene } \\
\text { por } 5 \text { minutos }\end{array}$ & $\begin{array}{l}\text { Streptococcuse } \\
\text { lactobacillus. }\end{array}$ & In vivo & $\begin{array}{l}\text { Tratamento } \\
\text { endodôntico }\end{array}$ & $\begin{array}{l}\text { A TFD demonstrou ter } \\
\text { vantagens e benefícios }\end{array}$ \\
\hline
\end{tabular}


Research, Society and Development, v. 10, n. 9, e48610918142, 2021

(CC BY 4.0) | ISSN 2525-3409 | DOI: http://dx.doi.org/10.33448/rsd-v10i9.18142

\begin{tabular}{|c|c|c|c|c|c|c|c|c|c|c|c|}
\hline & & & & & & & & & & convencional & $\begin{array}{l}\text { para o tratamento } \\
\text { endodôntico em relação à } \\
\text { técnica convencional. }\end{array}$ \\
\hline Silva et al. & 2010 & Brasil & Lasers de diodo & $685 \mathrm{~nm}$ & $35 \mathrm{mw}$ & $\begin{array}{l}30 \mathrm{a} \\
240 \mathrm{~s}\end{array}$ & $\begin{array}{l}\text { Azul de metileno } \\
\text { Por } 5 \text { min }\end{array}$ & E. Faecalis & In vitro & $\begin{array}{l}\text { Tratamento } \\
\text { endodôntico } \\
\text { convencional }\end{array}$ & $\begin{array}{l}\text { A instrumentação } \\
\text { associada à TFD foi } \\
\text { efetiva frente ao } e \text {. } \\
\text { Faecalis, mas não } \\
\text { eliminou totalmente. }\end{array}$ \\
\hline Braitt et al. & 2015 & Usa & - & - & - & $80 \mathrm{~s}$ & $\begin{array}{l}\text { Azul de metileno } \\
\text { Por } 5 \text { min }\end{array}$ & - & In vivo & $\begin{array}{l}\text { Tratamento } \\
\text { endodôntico } \\
\text { convencional }\end{array}$ & $\begin{array}{l}\text { Diante do exposto, pode- } \\
\text { se afirmar que, apesar da } \\
\text { controvérsia na } \\
\text { endodontia em relação ao } \\
\text { tratamento em sessão } \\
\text { única versus sessão } \\
\text { múltipla, o tratamento em } \\
\text { sessão única mostrou-se } \\
\text { bem-sucedido, }\end{array}$ \\
\hline
\end{tabular}

Fonte: Autores (2021) 


\subsection{Síntese dos Resultados}

Os principais resultados dos estudos incluídos apresentaram a terapia fotodinâmica (TFD) como uma técnica promissora quando utilizada como coadjuvante ao preparo químico mecânico para tratamento dos canais radiculares. O protocolo mais indicado dos estudos foi a utilização do fotossensibilizador azul de metileno durante 3 min para eliminação das bactérias, como a Streptococcus, Lactobacillus e E. faecalis. Como demostrados nos trabalhos, a TFD não pode ser usada de forma isolada nas infecções endodônticas, não devendo substituir o tratamento endodôntico convencional.

\section{Discussão}

Os resultados do levantamento dessa revisão integrativa demostraram que não existe um protocolo definido para TFD. Diferentes tipos de lasers foram citados nos estudos incluídos na presente revisão integrativa, sendo o laser diodo de baixa potência o mais utilizado. As conclusões dos estudos não apresentaram que um tipo de laser é superior a outro. Além da variação dos tipos de laser, diferentes tipos de ondas e potências também foram observados nos estudos, deixando em lacunas em aberto para futuras pesquisas.

Atualmente são utilizados lasers de diodo, emitindo no espectro vermelho em baixa intensidade, por serem bem absorvidos pelos tecidos biológicos (Garcez et al., 2016). Na terapia fotodinâmica, os efeitos obtidos não são por incremento de temperatura, mas por reações fotoquímicas entre o fotossensibilizador, luz e o substrato. com o objetivo de auxiliar na redução microbiana na faixa dos 99-100\%, quando utilizados em associação com agentes fotossensibilizadores (Alfenas et al. 2011; Rosa, 2008.; Santa-Rosa et al., 2019).

Com relação ao fotossensibilizador, os mais utilizados foram o azul de metileno e o azul de toluidina com o tempo variando de 2 a 5 minutos. Devido as grandes variações observadas nos parâmetros do protocolo de TFD, observadas nos estudos incluídos, não existe um consenso sobre quais são os melhores parâmetros para a elaboração e escolha do protocolo de aplicação. Assim, ficando a critério de cada profissional a construção do seu protocolo.

Nesta revisão integrativa, o laser de diodo foi um dos mais utilizados nos estudos incluídos. Com potência de 40mW e um tempo estimado de em 30 a 240 segundos. A faixa de comprimento de onda sugerida na literatura é entre 400-700 nm (dos Santos et al., 2017). Porém, o comprimento de 660nm parece ser o mais eficaz para inativar com sucesso as taxas relativas de microrganismos, como demonstrado na análise qualitativa da presente revisão integrativa (Poly et al., 2010).

Para a realização da TFD, corantes são utilizados para eliminação de microrganismo e são conhecidos como fotossensibilizadores. Diferentes tipos de corantes podem ser aplicados, incluindo o azul de metileno e o azul de toluidina, que foram os mais encontrados nos estudos dessa revisão (Almeida et al., 2019). Ambos em baixas concentrações não produzem ação citotóxica e a dose necessária para a morte bacteriana é menor que a dose para causar citotoxidade, eles têm sido utilizado como alvo para microrganismos da microbiota endodôntica, em razão de sua natureza hidrofílica, acompanhada de baixo peso molecular e carga positiva, o que permite a passagem através dos canais de proteínas porinas na membrana externa de bactérias gram-negativas (Simões et al., 2019).

Apesar desses corantes serem bastante aplicados, devido sua eficiência, ainda são necessários mais estudos para comprovação clínica, objetivando adotar esses corantes em um protocolo de execução (Plotino et al., 2019). Outro fator observado em protocolos para TFD é o tempo de irradiação, o qual é avaliado como o tempo entre a aplicação do fotossensibilizador na área e a ativação da luz. Esse tempo é importante para que ocorra a difusão do corante para o contato com os microrganismos. De forma geral, o tempo relatado nos estudos incluídos nesta revisão se estendeu aproximadamente por 2 a 5 minutos. A maioria dos estudos incluído são pesquisas in vitro, o levantamento de evidências científicas demonstrou 
Research, Society and Development, v. 10, n. 9, e48610918142, 2021

(CC BY 4.0) | ISSN 2525-3409 | DOI: http://dx.doi.org/10.33448/rsd-v10i9.18142

uma falta de padronização nos parâmetros do protocolo da TFD, bem como pesquisas in vivo. Assim, novas revisões e mais estudos clínicos devem ser desenvolvidos para comprovar nossos resultados e proporcionar informações relevantes para a construção de um protocolo claro e seguro da TFD.

\section{Conclusão}

A TFD mostrou-se promissora como coadjuvante ao tratamento endodôntico convencional para a limpeza dos canais radiculares. No entanto, faz-se necessário a realização de mais pesquisas, principalmente estudos clínicos, para a definição de um protocolo de utilização da TFD na prática clínica diária.

Os novos estudos a serem realizados devem seguir um rigor metodológico para que os resultados a serem analisados apresentem o mínimo de viés e maior confiabilidade. É interessante que seja feita a avaliação de diferentes de tipos de lasers de baixa potência, fotossensibilizadores e tempos de irradiação.

\section{Referências}

Albuquerque, M. (2012). Protocolos de revascularização pulpar. Monografia em Endodontia (Universidade Estadual de Campinas).

Alfenas, C. F. et al. (2011). Terapia fotodinâmica na redução de micro-organismos no sistema de canais radiculares. Revista Brasileira de Odontologia, 68(1), $68-71$.

Almeida, E. D. E. A. et al. (2019). Otimização da desinfecção pós preparo Químico-Mecânico. Revista Rede de Cuidados em Saúde, $13(1)$, 32-43.

Vianna, A. L. D. et al. (2011). Saúde, desenvolvimento e inovação tecnológica: nova perspectiva de abordagem e de investigação. Revista de Cultura $e$ Política, 83, 41-77.

Crossetti, M. G. O. (2012). Revisão integrativa de pesquisa na enfermagem: o rigor cientifico que lhe é exigido. Revista Gaúcha de Enfermagem, 33(2), 8-9.

Santos, K. R. R. et al. (2017). The importance of photodynamic therapy for decontamination of the root canal system: Case reports. Dental Press Endodontics, $7(3), 14-21$.

Eduardo C. P. et al. (2015). A terapia fotodinâmica como benefício complementar na clínica odontológica. Revista da Associação Paulista de CirurgiõesDentistas, 69(3), 226-235.

Garcez, A. S. et al. (2008). Antimicrobial effects of photodynamic therapy on patients with necrotic pulps and periapical lesion. Journal of Endodontics, 34(2), $138-142$.

Garcez, A. S. et al. (2016). Uma nova estratégia para PDT antimicrobiana em Endodontia. Revista da Associação Paulista de Cirurgiões-Dentistas, 70(2), $126-130$.

Melo, B. C. (2016). Medicação intracanal: Revisão de Literatura. Monografia em Endodontia (Universidade Federal de Minas Gerais).

Mendes, K. D. S., Silveira, R. C. C. P., \& Galvão, C. (2008). Revisão integrativa: método de pesquisa para a incorporação de evidências na saúde e na enfermagem. Texto \& Contexto - Enfermagem, 17(4), 758-764.

Moher, D. et al. (2009). Preferred reporting items for systematic reviews and meta-analyses: The PRISMA statement. PLoS Medicine, 6(7), 1-6.

Mortoza, T. D. \& Longo, D. L. Tratamento endodôntico: sessão única. Monografia em Endodontia (Universidade de Rio Verde).

Plotino, G., Grande, N. M., \& Mercade, M. (2019). Photodynamic therapy in endodontics. International Endodontic Journal, 52(6), 760-774.

Poly, A. et al. (2010). Efeito antibacteriano dos lasers e terapia fotodinâmica contra Enterococcus faecalis no sistema de canais radiculares. Revista de Odontologia da UNES, 39(4), 233-239.

Rosa, F. C. S. (2008). Eficácia da instrumentação associada à terapia fotodinâmica antimicrobiana e medicação intracanal na eliminação de biofilmes e na neutralização de endotoxinas em camais radiculares. Tese de Doutorado (Universidade Estadual Paulista).

Santa-Rosa, C. C. et al. (2019). Estudo piloto da análise comparativa da atividade antimicrobiana da PDT e agentes irrigantes em canais radiculares inoculados com Enterococcus faecalis “in vitro.” Arquivos em Odontologia, 55(1), 1-8.

Amaral R. R. et al. (2019). Terapia fotodinâmica na endodontia: revisão de literatura. Journal of Oral Investigations, 8(1), 86-99.

Simões, T. M. S. et al. (2019). Aplicabilidade da terapia fotodinâmica antimicrobiana na eliminação do Enterococcus faecalis. Archives of Health Investigation, 7(11), 492-496. 
Research, Society and Development, v. 10, n. 9, e48610918142, 2021

(CC BY 4.0) | ISSN 2525-3409 | DOI: http://dx.doi.org/10.33448/rsd-v10i9.18142

Soukos, N. S. et al. (2006). Photodynamic Therapy for Endodontic Disinfection. Journal of Endodontics, 32(10), 979-984.

Torabinejad, M., \& Turman, M. (2011). Revitalization of tooth with necrotic pulp and open apex by using platelet-rich plasma: A case report. Journal of Endodontics, 37(2), 265-268.

Sivieri-Araújo, G. et al. (2013) Terapia fotodinâmica na Endodontia: emprego de uma estratégia coadjuvante frente à infecção endodôntica. Dental Press Endodontics, 3(2), 52-8.

Santos, M. G. C. et al. (2017). Análise do uso da terapia fotodinâmica no tratamento endodôntico com base em um congresso odontológico. Revista da Faculdade de Odontologia da UFF, 22(1), 49-53.

Silva, F. C. et al. Análise da efetividade da instrumentação associada à terapia fotodinâmica antimicrobiana e a medicação intracanal na eliminação de biofilmes de Enterococcus faecalis. Brazilian Dental Science, 13(5), 31-38. 